well as its meaning, and phenomenological descriptions cannot overlook it. Does the phenomenon that interests us take place in a particular context, say, a medical, political, or academic one? If so, what bearing does this context have on how the phenomenon is experienced by various agents?

\section{Awareness of the Pliability of Experience}

Phenomenologists must avoid the error of treating experience or its forms as absolute constants that once altered are forever destroyed. Experience is a dynamic system that is constantly being shaped by our interpretation of the world (Merleau-Ponty 2013; Heidegger 1996). Hence, inquiries into different kinds of experiences must not only look at the experiences themselves but also how they are interpreted and reinterpreted by actors in various situations.

\section{Humility About the Reach of Theory}

At its very core, phenomenology is a clarion call against the tyranny of theory. Now, by this I do not mean that phenomenology is anti-intellectual or anti-theoretical (the opposite is true). I mean instead that phenomenology has historically made the case that the source of the most fundamental truths is not theoretical knowledge but lived experience. Experience is the site where the most primitive of norms are born (Peña-Guzmán 2013). As such, to remain faithful to the spirit of phenomenological inquiry, one must make the contents of theory answerable to the contents of experience and not the other way around.

\section{REFERENCES}

Elliott, I., L. Lach, and M. L. Smith. 2005. I just want to be normal: A qualitative study exploring how children and adolescents view the impact of intractable epilepsy on their quality of life. Epilepsy $\mathcal{E}$ Behavior 7(4): 664-78

Gilbert, F. 2015. A threat to autonomy? The intrusion of predictive brain implants. AJOB Neuroscience 6(4): 4-11.

Glannon, W. 2015. Neuromodulation, agency and autonomy. Brain Topography 27(1): 46-54.

Heidegger, M. 1996. Being and time. Albany, NY: SUNY Press.

Husserl, E. 1970. The crisis of European sciences and transcendental phenomenology: An introduction to phenomenological philosophy. Evanston, IL: Northwestern University Press.

Husserl, E. 2001. Logical investigations, ed. D. Moran. London, UK: Routledge.

Matrin, W., and R. Hickerson. 2011. Mental capacity and the applied phenomenology of judgement. The Essex Autonomy Project. Available at: http://autonomy.essex.ac.uk/mental-capacityand-the-applied-phenomenology-of-judgement (accessed August $7,2015)$.

Merleau-Ponty, M. 2013. Phenomenology of perception, trans. D. Landes. New York NY: Routledge.

Peña-Guzmán, D. 2013. Pathetic normativity. Chiasmi International 15: 361-84.

Roberts, R. J., et al. 1992. The phenomenology of multiple partial seizure-like symptoms without stereotyped spells: An epilepsy spectrum disorder? Epilepsy Research 13(2): 167-77.

\title{
Do Predictive Brain Implants Threaten Patient's Autonomy or Authenticity?
}

\author{
Eldar Sarajlic, City University of New York
}

The development of predictive brain implant (PBI) technology that is able to forecast specific neuronal events and advise and/or automatically administer appropriate therapy for diseases of the brain raises a number of ethical issues. Provided that this technology satisfies basic safety and functionality conditions, one of the most pressing questions to address is its relation to the autonomy of patients. As Frederic Gilbert in his article (Gilbert 2015) asks, if autonomy implies a certain idea of freedom, or self-government, how can an individual be considered to decide freely if the implanted device stands at the inception of the causal chain producing his decisions? He claims that PBIs threaten persons' autonomy by diminishing their postoperative experience of selfcontrol.

In this commentary, I discuss this claim. Contrary to Gilbert, I suggest that PBIs do not pose a significant threat to patient's autonomy, as self-control, but rather to his or her sense of authenticity. My claim is that the language of authenticity, already introduced in the recent bioethical literature, may offer a better way to voice some of the concerns with PBIs that Gilbert recognized. 


\section{AUTONOMY}

Gilbert takes over the definition of autonomy from Alfred Mele (1995) and claims that autonomy refers to the person's exercise of control over her choices. He reports the experience of a patient who volunteered to be implanted with an experimental PBI. The patient, who has suffered from epilepsy seizures for more than 20 years, claims that the device has given him more control over his life, thus confirming that PBIs can be compatible with personal autonomy. However, Gilbert suspects that this reported control is not sufficient for autonomy because the phenomenology of autonomy, or the patient's subjective experience of self-control, may be diminished due to the influence of the device.

According to Gilbert, the persons with PBIs have no control over the predictions or automated responses of the devices, and thus have a diminished experience of acting autonomously. Gilbert thinks this subjective experience of autonomy is valuable because a person's sense of autonomy is fundamental to postoperative iatrogenic harms. Patients' first-person view is a constitutive part of their own narrative identity, and it enables them to "report restorative or deteriorative feelings of autonomy and selfestrangement following surgery" (6). While a PBI provides more sense of control to the patients, it simultaneously makes them overly reliant on the device and thus prevents them from recognizing potential risks and reacting to "other stimuli that may guide them just as well" (8). When patients' decisional abilities are influenced by PBIs, they may become passive and experience a sense of powerlessness that threatens their postoperative sense of control. With overreliance on PBIs, "it is not clear where the realm of decisional autonomy starts and where the realm of advice ends" (8).

Although I do share these concerns about potential effects of predictive brain implants, I think the language of autonomy may not offer the best conceptual tool for recognizing and addressing the contentious issues at hand. I propose we reconceptualize the problem by referring to patients' authenticity.

\section{AUTHENTICITY}

Consider Gilbert's main claim again. While he seems to concede that with the PBI the patients' control over their life is increased, rather than decreased (especially given the reports by the volunteer patient), he suggests something similar, yet, as we shall see, sufficiently different: The fact that persons with PBIs have no control over the advice and predictions threatens their experience of autonomy. He doesn't elaborate the potential difference between autonomy and the experience of it. Is the person's experience of self-control synonymous with autonomy? I suggest not, because what Gilbert is describing seems more akin to the concept of authenticity, rather than autonomy.

While autonomy refers to the agent's ability for selfgovernance and rational reflection, authenticity introduces the idea that some elements of the person's self outweigh requirements of rational reflection and self-control (see Varga 2012; Gugnon 2004). This is because some features of the individual's personality may be so fundamental to his or her identity that overriding them through rational reflection would endanger the cohesiveness of that person's self. In cases of patients with brain diseases such as epilepsy, by advising, or automatically preventing certain outcomes, the PBI can alter the patient's sense of identity because the illness may have become an integral part of his or her conception of self. The person perceives herself and builds understanding of the world through the lens of the disease (see the "case of the Dutch patient" elaborated by Kraemer [2013a]; also see Kraemer [2013b]).

The postoperative sense of powerlessness and loss of control may not necessarily be associated with the diminishing ability of the person to exercise control over his or her actions. Contrary to that, as reported by the volunteer patient, the sense of control over a patient life may even increase. What may decrease, however, could be the patient's experience of control over his or her identity, and the patient's identity-based interaction with the environment. Therefore, a potential consequence of the introduction of PBIs to patients with brain diseases will be a partial loss of authenticity. They may feel that they are not "their usual selves" and experience a (partial, and as I suggest, temporary) form of alienation from the core of their identity.

This may be an encouraging development for the patient. Being free from illness as a defining, if not constitutive, element of their old selves may be empowering and liberating. However, this is also where the potential threat of iatrogenic harm lies. If a person is accustomed to a certain identity-based relation to his or her surroundings, and if the brain condition has become a part of the person's strategies of interaction and survival, the introduction of a PBI may plausibly alter the person's sense of familiarity with the new structures of this relation. To understand what I mean by this, consider one of the main dimensions of the concept of authenticity developed by Alessandro Ferrara (1998). Besides coherence, vitality, and maturity of a person's identity as a prerequisite for authenticity, Ferrara posits that depth is one of its constitutive conditions. The dimension of depth, for Ferrara, "designates a person's capacity to have access to his or her own psychic dynamisms and to reflect such awareness in the construction of his or her identity" (Ferrara 1998, 96). It is plausible to suggest that the introduction of a PBI to a person's everyday mode of psychological operation and social interaction changes her psychic dynamism, including the ways she understands herself and her relation to the world. She may simultaneously exercise more control over her actions, by being able to predict or automatically prevent a seizure with the advisory help of the PBI, but her sensation of the depth of her identity will be altered by the device, and can potentially lead to harms associated with excessive (or unjustified) reliance on the PBI and the ensuing false sense of security. Patients could willingly get 
themselves in potentially harmful situations that they would not have normally entered had their access to their own psychic dynamism and the psychic structures for interaction with the environment not been altered by the PBI.

\section{IS THREAT TO AUTHENTICITY A SERIOUS CONCERN?}

The preceding discussion has tried to show that it is not patients' autonomy but their authenticity that is potentially threatened by the PBIs. I believe the vocabulary of authenticity gives us a clearer picture of what may be a problem with the introduction of this revolutionary medical technology.

The vocabulary of authenticity can also indicate that the ethical challenge PBI poses to the patients' sense of selves can be met and (hopefully) resolved. While any threat to patients' autonomy in medical practice is considered a serious hurdle to be overcome either by altering the way technology is applied and therapy administered or by finding ways to increase patients control over their bodies, the problem with PBIs and authenticity is easily resolvable. This is simply because a person's identity is permanently evolving, and patients can recover the partial loss of authenticity (gaining "depth") by adapting gradually to the new psychic dynamisms and learning how to navigate the environment based on the introduction of the new element in their identities.
While challenging on its own right, this is not an insurmountable problem, since human identities are narrative constructs that change over time, adapt to new realities, and find ways to function well, or even flourish, despite the illness. This suggests that a possible remedy to the partial loss of authenticity induced by the introduction of PBIs should include postoperative adjustment therapies, through which patients can reconceptualize their new selves and learn to navigate the new structures of relating to the world.

\section{REFERENCES}

Ferrara, A. 1998. Reflective authenticity: Rethinking the project of modernity. New York, NY: Routledge.

Gilbert, F. 2015. A threat to autonomy? The intrusion of predictive brain implants. AJOB Neuroscience 6(4): 4-11.

Gugnon, C. 2004. On being authentic. New York, NY: Routledge.

Kraemer, F. 2013a. Authenticity or autonomy? When deep brain simulation causes a dilemma. Journal of Medical Ethics 39: 757-60.

Kraemer, F. 2013b. Me, myself and my brain implant: Deep brain simulation raises questions of personal authenticity and alienation. Neuroethics 6: 483-97.

Mele, A. 1995. Autonomous agents: From self-control to autonomy. Oxford, UK: Oxford University Press.

Varga, S. 2012. Authenticity as an ethical ideal. New York, NY: Routledge.

\title{
Are Brain-Computer Interface (BCI) Devices a Form of Internal Coercion?
}

\author{
Eran Klein, Oregon Health and Science University, Neurology Service, Portland Veterans \\ Administration Medical Center and University of Washington
}

Internal coercion has been proposed as an amendment to standard criteria of autonomous choice in bioethics (Müller and Walter 2010). Alongside a criterial triad of acting (1) with intention, (2) with understanding, and (3) with freedom from overwhelming controlling influence of others, internal coercion fills a perceived void (Beauchamp and Childress 2013). Accounts of autonomy in bioethics can leave out threats to autonomous choice that originate from inside the person. Paradigmatic examples of internal coercion include pathological conditions of the brainschizophrenia, severe depression, traumatic brain injury, and others. It has been suggested that brain-computer interface (BCI) devices be added to this list of potential sources of internal coercion (Gilbert 2015). While BCI devices may threaten autonomy in important respects, it will be argued that conceiving of such threats as a form of internal coercion is premature.

The notion of internal coercion in bioethics derives largely from a rough, intuitive distinction between internal and external threats to medical decision making. External threats reside outside the individual. Medical professionals, family members, institutional representatives, all those who interact with patients are a potential source of external influence on medical decision making. Influence

Address correspondence to Eran Klein, Department of Neurology, Oregon Health and Science University, 3181 SW Sam Jackson Park Road, CR131, Portland, OR 97239, USA. E-mail: kleine@ohsu.edu 